\title{
Love and Breakup Letter Methodology: A New Research Technique for Medical Education
}

DOI:

10.1111/medu.14463

\section{Document Version}

Accepted author manuscript

Link to publication record in Manchester Research Explorer

\section{Citation for published version (APA):}

Laughey, W. F., Brown, M. EL., Liu, A., Dueñas, A. N., \& Finn, G. M. (2021). Love and Breakup Letter Methodology: A New Research Technique for Medical Education. Medical education.

https://doi.org/10.1111/medu.14463

\section{Published in:}

Medical education

\section{Citing this paper}

Please note that where the full-text provided on Manchester Research Explorer is the Author Accepted Manuscript or Proof version this may differ from the final Published version. If citing, it is advised that you check and use the publisher's definitive version.

\section{General rights}

Copyright and moral rights for the publications made accessible in the Research Explorer are retained by the authors and/or other copyright owners and it is a condition of accessing publications that users recognise and abide by the legal requirements associated with these rights.

\section{Takedown policy}

If you believe that this document breaches copyright please refer to the University of Manchester's Takedown Procedures [http://man.ac.uk/04Y6Bo] or contact uml.scholarlycommunications@manchester.ac.uk providing relevant details, so we can investigate your claim.

\section{OPEN ACCESS}




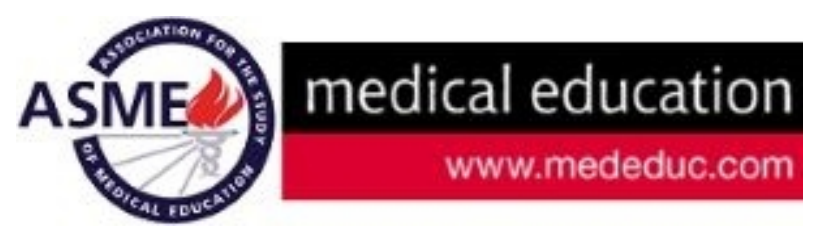

\section{Love and Breakup Letter Methodology: A New Research Technique for Medical Education}

\begin{tabular}{|r|l|}
\hline Journal: & Medical Education \\
\hline Manuscript ID & MED-2020-2805.R2 \\
\hline Manuscript Type: & Research Approaches \\
\hline Keywords: & Instructional Materials/Methods, Interdisciplinary Medical Education \\
\hline Research Method: & Knowledge synthesis (i.e., review article) \\
\hline \multicolumn{2}{|l}{} \\
\hline
\end{tabular}

\section{SCHOLARONE \\ Manuscripts}


Page 1 of 19

\section{Love and Breakup Letter Methodology: A New Research Technique for Medical Education}

Authors:

William F Laughey*a, Megan EL Brown ${ }^{\mathrm{a}}$, Ariel Liu ${ }^{\mathrm{b}}$, Angelique N Dueñas ${ }^{\mathrm{a}}$ and Gabrielle M Finn ${ }^{\mathrm{a}, \mathrm{c}}$

${ }^{a}$ Health Professions Education Unit, Hull York Medical School, York, UK

${ }^{b}$ Google Inc, Mountain View, California, USA

${ }^{c}$ Division of Medical Education, School of Medical Sciences, Faculty of Biology, Medicine and Health, The University of Manchester, Manchester, UK.

*Corresponding author contact details: William.Laughey@hyms.ac.uk

Health Professions Education Unit, Hull York Medical School, York, YO10 5DD, UK

Biographical notes:

William F Laughey is a General Practitioner and clinical tutor.

Megan EL Brown is a PhD student in medical education.

Ariel Liu is a Staff User Experience Researcher at Google.

Angelique N Dueñas is a $\mathrm{PhD}$ student in medical education.

Gabrielle M Finn is a professor of medical education and vice-dean for teaching, learning and students. 
Page 2 of 19

(Words 3420, excluding boxes.)

\section{Introduction}

We have recently utilised Love and Breakup Letter Methodology (LBM) ${ }^{1,2}$ in medical education research ${ }^{3}$, the first time this has been reported in the literature. LBM was developed within the discipline of User Experience (UX) ${ }^{4}$, where it is typically used as a tool to capture what focus group participants like or dislike about technological features or sites. ${ }^{2}$ Research participants are asked to write a love or breakup letter before, or at the beginning of, the focus group. They read their letter aloud to the rest of the participants, and the points expressed within their letters then form the prompts for the focus group discussion that follows. ${ }^{2}$ In this paper, we set out the theoretical considerations for LBM, consider its background in UX, and discuss its practical use in medical education.

\section{$L B M$ in $U X$}

UX first came to prominence in the mid 1990s and since has grown into a buzzword for the Human- Computer Interaction (HCI) among community practitioners and researchers who focus on understanding and improving the human computer interface ${ }^{5}$. As technology advances, UX research has gone beyond typical usability studies or interviews, and now centres on understanding a user's emotional and internal state in relation to "the designed 
Page 3 of 19

system and the context within which the interaction occurs. "' UX research methodology has also been used outside of technology, notably in libraries, where it has been used to influence the design of library space and the services on offer. ${ }^{6}$ Many qualitative UX research methods will be familiar to medical educators, including individual interviews, observational field studies, diary studies, and focus groups., ${ }^{7,8}$

LBM is based on the premise that users form emotional attachments to their devices, apps, and websites - they have feelings for them ${ }^{8}$. These feelings are important as they can change the human decision-making process. For example, feelings can dictate whether a user remains loyal to a brand, or switches to another ${ }^{1}$. Although LBM is concerned with both feelings and emotions, there are differences between the two. Definitions of emotions and feelings are complex and contested, and it is beyond the scope of this paper to consider these in detail. Generally, emotions are viewed as powerful reactions involving syncronised changes to physical and mental functions, linked with neuro endocrine and autonomic changes such as those found in the fight or flight response ${ }^{9}$. Feelings are one component of emotions, and operate at the more conscious and subjective level of the cognitive appraisal of emotional states ${ }^{9}$. Given that LBM requires participants to articulate their thoughts about their attachments to technologies, it may also encourage them towards some subjective, cognitive appraisal of their emotions - in other words, help translate their emotions to feelings.

Love and break up letters are age-old techniques for getting feelings and emotions out in the open. ${ }^{1}$ The literature of love letters dates back to at least the ancient Roman period ${ }^{10}$. LBM is able to exploit this traditional device for the airing of feelings by asking participants to personify the concept under study and make this the object of the letter. As Gerber suggests, 
Page 4 of 19

LBM helps participants express feelings they otherwise might struggle to articulate in more traditional interview-based approaches ${ }^{8}$.

\section{LBM and Medical Education}

LBM should also have utility in medical education, because feelings are central to many of its key concepts ${ }^{11,12}$, including clinical empathy; ${ }^{13}$ resilience; ${ }^{14}$ professional identity formation; ${ }^{15}$ feedback; ${ }^{16}$ and questions of bias ${ }^{17}$. Even in the more deductive areas of medical practice, such as clinical reasoning, feelings have their part to play. ${ }^{18}$ Potentially, then, there is a wide field of educational research to which LBM could reasonably be applied.

As with UX research, we anticipate that love and breakup letters in medical education will be most naturally utilised within the focus group setting. By effectively providing an audience, the public nature of focus groups sharpens anticipation for the creative writing and recital components of LBM. In our experience, this modest sense of theatre raises the energy of the focus group meeting as a whole, elevating enthusiasm for the discussion that ensues.

However, there is no reason to limit the use of LBM exclusively to focus group methodology.

Considered as a more flexible concept, love and break-up letters have relevance for survey design, individual interviews, and programme evaluation.

Love and break up letters could also be considered as a form of standalone reflective writing. While such letters may not form the typical template for medical reflection, they do none-theless capture the author's lived experiences, thoughts, and feelings. As such, they are aligned 
Page 5 of 19

with the aims of reflective writing in medical education ${ }^{19}$ and offer a refreshing alternative to formulaic reflective templates that risk undermining the value of educational portfolios. ${ }^{20}$ Furthermore, expressive writing of this kind has been linked to improvements in mental health and well-being. ${ }^{21}$

\section{LBM and paradigms}

Epistemologically and ontologically, users of LBM make several assumptions. Love and breakup letters are subjective "discursively constructed tales of emotion," which do not allow objective verification of a participant's exact feelings. ${ }^{1}$ As such, their use best aligns with constructivist ways of viewing the world. Constructivism maintains that there is no one objective reality or way of knowing, instead individuals subjectively construct reality and knowledge. ${ }^{22}$

LBM may also fit with constructionist understandings of the world. Constructivism and constructionism are often used interchangeably, but they do differ. ${ }^{23}$ Whilst constructivism focuses on the individual, constructionism is concerned with groups. Maintaining that reality and knowledge exist within social interactions, constructionism posits that these entities are co-constructed in the space between individuals. ${ }^{24}$ Letter writing is a social endeavour, ${ }^{25}$ and the group discussion of love and breakup letters can be used, through a constructionist lens, to explore how individuals co-construct meaning as a collective. 
Page 6 of 19

Finally, LBM also suits use within a pragmatic paradigm, a way of conducting research focusing on problem solving within the 'real world'. ${ }^{26}$ In the post-paradigm war era, researchers in the pragmatic paradigm accept the combination of post-positivist and constructivist approaches within the same research study, usually in the form of mixedmethods design incorporating both quantitative and qualitative elements ${ }^{26}$. A survey-based study collecting both quantitative and qualitative data could include an invitation to write a love or break up letter as part of the qualitative data-gathering. Within UX, LBM is often combined with methods that adopt quantitative approaches, such as card-sorting ${ }^{2}$, typifying a pragmatic approach. For example, when researching an app, LBM is employed to understand how users relate to the product, while card sorting - a method in which participants group information written on cards in ways that make sense to them ${ }^{2}$ - is employed to explore how users prefer content to be displayed.

\section{LBM in practice}

LBM is inherently flexible, so researchers in medical education have options as to how they wish to adapt the approach to their particular area of study. To guide the reader further, we will first consider the archetypal approach to running an LBM focus group in UX, then we will describe how we have adapted this for research in medical education.

\section{Practice points from a UX researcher}


Page 7 of 19

As industry UX researchers collect data that is commercially sensitive, few studies concerning such data have been published in peer-reviewed journals. The literature, therefore, provides only superficial details of how the LBM methodology is employed in UX. Thus, as an illustrative aid, we have included these practical considerations from a staff UX researcher at a technology company (one of the authors, AL, from this paper).

One important fact to note is that in the technology sector, LBM is often used in conjunction with other activities, such as interviews or Card Sorting 2 , as part of a co-creation workshop with participants. These combinations are motivated either by a concern for participant fatigue caused by an activity that extends for a longer duration, or by the desire to keep them engaged with the topic areas. Typically, researchers follow these steps:

1. To examine participants' emotions about an aspect of technology, participants are often asked to interact with the platform or feature from their mobile devices for the first five minutes of the session. Each participant is then asked to spend no more than fifteen minutes writing a short love or breakup letter about this experience. The goal is to capture participants' immediate thoughts and emotions when engaging with the platform or feature. To avoid confusion or embarrassment, a simple example letter is exhibited in front of them to boost participant confidence.

2. When the letters are completed, the facilitator records each participant reading aloud their letters to their phones as if they were sending video messages. This approach heightens participants' emotions, and sometimes, it brings out the humorous aspects of the experience. 
Page 8 of 19

3. Each time a participant finishes reading a letter, the facilitator asks other participants to raise their hands if they feel the same way and then asks the author follow-up questions. This review process not only helps the participants get to know each other, but it also makes the discussion environment more relaxed, conversational, and relatable. The facilitator, who is often the researcher, has a critical role in this activity. When the participants are not as vocal, the researcher must come up with prompts to promote dialogue and sharing.

4. In the workshop, there is often another researcher who acts as the note-taker, capturing the key topics discussed in addition to the letters.

5. Occasionally, after the LBM activity, participants are asked to participate in an ideation phase and redesign their ideal relationships to amend or improve their relationships with the platform or feature at issue. This helps the researcher identify the trade-offs and challenges from the users' perspectives as well as the potential solutions, or at least gain a deeper understanding of the problems.

\section{Practice points in medical education}

In studying clinical empathy ${ }^{3}$, we adopted the following three-step approach to LBM in medical education:

1. Participants wrote their love and break up letters to the concept under study (e.g., 'empathy for patients,' which was our concept being researched) at the beginning of the meeting. We asked for both a love letter and a breakup letter from each 
Page 9 of 19

participant. Letters were hand-written, though the option of writing electronically saves transcribing. We allowed 20-30 minutes for writing.

2. Letters were read aloud, in turn, by their authors. Participants read their love letter first, and when all love letters had been read, they moved onto the breakup letters. The research team noted key messages and other relevant field observations but held off from instigating any discussions until all letters had been read.

3. The facilitator used the letters and their messages as the triggers for the focus group discussion. A typical discussion time was 50 minutes.

The task of letter writing usually takes place at the beginning of the session with the researchers in the room. This allows for the opportunity of explaining the letter-writing task, answering any questions, and generally making sure that participants are comfortable with what is required. Session time could be saved by asking participants to bring pre-written compositions, but this option would not provide the same in-person clarification about the letter-writing process.

Researchers have a choice as to whether to ask participants to write either a love letter or a breakup letter, to compose a single letter that starts with love and moves to break up or to write both a love letter followed by a breakup letter. We chose the latter method, reasoning it would help participants consider both sides of the argument and perhaps encourage a more balanced discussion. In UX, it is common to give participants the choice of either love or break up, partly in the interests of time, partly because it may be more acceptable to 
Page 10 of 19

participants, and also because it is interesting to know from the beginning which way participants are leaning.

In our study, we elected for all letters to be recited before commencing the discussion. We reasoned this would prioritise the collective discussion element over the individual letters, following a more traditional focus group approach in medical education. This approach may also work better for groups in which power or hierarchy merit consideration, such as focus groups with interprofessional learners. If taking the alternative approach of inviting discussion after each letter, a participant who feels lower in the hierarchy may be reluctant to read a letter that contains ideas that have already been adversely received by those at the top of the hierarchy. However, there may be instances where researchers feel that the individual contributions in the letters should be prioritised over the fluidity of a continuous group discussion, in which case inviting discussion after each letter would make more sense.

In UX, letter reading is often video recorded ${ }^{2}$. Though in our use in medical education, we elected to use audio recording for the letter readings and focus group discussion. We reasoned that video recording would add an extra layer of embarrassment to an activity that might already feel daunting for shy participants. However, by providing the opportunity to consider body language, video recording may allow researchers to better understand any unspoken messages, "to read between the lines" of the letters.

In UX, participants recite their letters to their smart phones. The phone here works largely as a prop, helping with the aspect of performance. Phones can also capture video recordings, which UX researchers use to enhance the presentation of their findings within their company meetings. Anticipating our output would be a written paper, we elected not to capture any 
Page 11 of 19

video and did not ask participants to recite to their phones. In retrospect, we may have missed an opportunity to enhance the presentation of findings at an academic conference.

As with any other type of focus group, the role of the facilitator merits consideration. The facilitator has all the usual responsibilities common to focus groups, such as encouraging contributions from all participants, ${ }^{27}$ but in addition, they also need to be alert to the potential for embarrassment associated with letter reading. In our limited experience in medical education, embarrassment is often less of a problem than might be anticipated. However, this comes with the caveat that we recruited groups of students who often knew each other, having studied together for several years. In addition, one researcher (WFL) was known to several participating students as a phase one tutor, which may also have helped participants accept the methodology.

The facilitator, aided by the research team, also needs to be alert to the key messages apparent in the letters, as these will form the triggers for the discussion to follow. The wider research team should make field notes during the discussion, supporting the facilitator in identifying key messages and noting non-verbal communications that are lost with audiorecording.

Finally, recognising that LBM is more likely to be used for emotive areas of study, the facilitator and the research team as a whole need to be alert to the possibility of participants becoming uncomfortable or feeling distressed at any point in the research meeting. The consent process should accommodate this potential concern and detail procedures for debriefing afterwards should this be needed. 
Page 12 of 19

\section{LBM Merits and Limitations}

We believe that LBM has a number of merits. Used in conjunction with focus groups, LBM ensures that all members of the group contribute their initial thoughts. These thoughts have not yet been subject to group influence, so they represent valuable, individual contributions. In this way, LBM mitigates a general limitation of focus groups, that quieter participants might be overshadowed by more vociferous members of the group. ${ }^{27}$

Letter writing requires the use of heightened language, including literary devices, such as personification, hyperbole, metaphor, and rhyme. ${ }^{28}$ This figurative language captures richer messages, which themselves translate to richer data for analysis. Medical education, like UX research, deals with abstract constructs. Personifying the abstract - for example, "empathy for patients" - and inviting creative writing centred on feelings and emotions is certainly an interesting and engaging way of inviting discussion. In our experience, the letters are often both captivating and humorous. They act both to raise interest in the topic and serve as "ice breakers" for the discussion to follow. In our medical education research, students generally took to the task of letter writing with enthusiasm and no small amount of artistic flair. ${ }^{3} \mathrm{We}$ have included examples of two letters by way of illustration. (Box 1).

Conversely, it is also important to consider the limitations of LBM. By their nature, love and breakup letters are dichotomous, risking a focus on opposing ends of the spectrum and missing the shades of grey in between. As already discussed, some participants are less comfortable with creative writing and potentially may be embarrassed to read their letters. This warrants consideration during the process of consent. In terms of practicalities, letter 
Page 13 of 19

writing increases the duration of the focus group, adding 20-30 minutes in the empathy study (though generally a little less time, around 10-15 minutes, is used in UX research).

Case studies in Medical Education

1 Focus Group

Within medical education, we used LBM in a focus group setting to research medical students' thoughts and feelings on the practice and teaching of clinical empathy. ${ }^{3}$ We asked for love and breakup letters regarding the concept of empathy for patients. We ran three focus groups and analysed the written letters and the discussion transcripts together, using Thematic Analysis. ${ }^{29}$ Almost all of the student participants warmed to the task of letter writing, producing remarkable compositions (Box 1). The letters, and the discussions they prompted, provided rich data for analysis. The method worked well for getting to the root cause of the matter. For example, we quickly uncovered the problem of making fake empathic statements ${ }^{3}$.

We also had the opportunity to conduct LBM online. The third focus group was conducted using video-conferencing software, due to the social distancing restrictions mandated in the wake of COVID-19. Online focus groups are by no means a new concept ${ }^{27}$, and they will be more necessary through the duration of the pandemic and may remain more popular after it. Perhaps the most noticeable difference came during the process of letter reading. Extraneous noises and feedback interrupted one reading, so as a group we switched to mute to hear the letters without background interruptions. However, this also reduced the sense of support, as 
Page 14 of 19

well as the warmth and laughter that typically accompanies an in-person reading. None-theless, letters and discussion yielded data just as rich as those from the first two focus groups, and the recording feature built into the video-conferencing software meant we could capture both audio and video with ease.

\section{In Programme-Level Research}

LBM can also be modified for use alongside other qualitative methods, outside of focus groups. We have also used LBM as open-ended response questions in a qualitative survey researching the impacts of a large-scale widening access programme intended to give participants from relatively under-privileged backgrounds access to medical school. Participants were asked to write love and break-up letters to their programme, in lieu of more traditional 'positive' and 'negative' experience questions. While simple, this use of LBM highlighted the power of personification. Responses were emotive, with participants having to personify their participation in the programme. As part of this research study, semistructured interviews were then conducted to follow-up with some participants. Similar to their use in focus groups, the letters also provided an excellent stimulus for discussion, to help guide participant reflection about their lived experiences.

\section{LBM in Teaching Evaluations}

Following the success and insight from using LBM in programme-level research, we also employed LBM in more small-scale, routinely collected programme evaluation. A novel professionalism and ethics ten-week workshop series was created. To assess the innovation, 
Page 15 of 19

each week, students were informally asked to write a love and break-up letter to the content and activities covered in that session. However, this means of using LBM highlighted some limitations. With limited time, and when prompted to reflect on specific content, this methodology did not produce responses beyond what may have also been elucidated via more simple evaluation. Additionally, as students repeated feedback weekly, detail in response waned. This warrants consideration of the possible longitudinal value of LBM for other topics or types of research; LBM might best be utilised in singular, cross-sectional research.

In summary, our experience highlights the power of LBM, particularly when used in multimethods approach to research or evaluation. While letters can be powerful alone, insights are even greater when investigators have the opportunity to use letters as a springboard for discussion. Applied judiciously, with due consideration for merits and limitations (Box 1), LBM has clear potential for use in research and evaluation within medical education.

\section{Box 1: Merits \& Limitations of LBM}

Merits

- Ensures individual contributions from all participants

- Acts as an icebreaker since the letter reading encourages smiles and laugher

- Creative writing \& recitals elevate interest and engagement, fuelling focus group discussion

- Aligns with the practice of reflective writing, an already well-established tool in medical education 
Page 16 of 19

- Provides additional rich data from the letters for analysis

Limitations

- Risk of dichotomous data and neglected shades of grey

- Socially uncomfortable for some participants

- Extends duration of focus group session

- Less well suited to repetitive use in longitudinal approaches

\section{Box 2: Sample Letters}

\section{Love}

Empathy, I love you, you're the most real and important factor in a consultation. You're strong and powerful and your presence can make everything more interesting. Although you are often absent, I know our time together is invaluable. When you're around, I listen more, care more, and learn more. The more I have got to know the real you, the more in love I am. I still remember the first time we met, it was on the gastro ward, the sun was streaming in through the window and I felt you, it was real love. I still remember that consultation and I hope we have the rest of our lives together.

Lots of love, $x x x$ 
Page 17 of 19

\section{Breakup}

Dear Empathy...

You will always hold a place in my heart,

But it breaks me to say, I'm afraid we must part.

You've always been there, always something to say,

But for me, I'm afraid, that is just not $O K$.

Silence speaks volumes, it allows time to think,

Not just empty fillers, like a carbonated drink.

You have so much potential to really have meaning,

But forced words is the way you are leaning.

I know there's someone out there for you,

You need to be yourself, don't change, stay true.

You have so many wonderful qualities to see,

But I am sorry, Empathy, you are just not for me.

\section{References}

1 Koskinen K, Ruokonen M. Love letters or hate mail? Translators' technology acceptance in the light of their emotional narratives. In: Human issues in translation technology 2017 Jan 12 (pp. 26-42). Routledge.

2 Hanington B, Martin B. Universal methods of design: 100 ways to research complex problems, develop innovative ideas, and design effective solutions. Rockport Publishers. 2012. 
Page 18 of 19

3 Laughey WF, Brown ME, Dueñas AN, Archer R, Whitwell MR, Liu A, Finn GM. How medical school alters empathy: Student love and break up letters to empathy for patients. Medical Education. 2020 Oct 30.

4 Hassenzahl M, Tractinsky N. User experience-a research agenda. Behaviour \& information technology. 2006 Mar 1;25(2):91-7.

5 Lallemand C, Gronier G, Koenig V. User experience: A concept without consensus? Exploring practitioners' perspectives through an international survey. Computers in Human Behavior. 2015 Feb 1; 43:35-48.

6 Schmidt A, Etches A. User experience (UX) design for libraries:(THE TECH SET®\# 18). American Library Association; 2012.)

7 Rohrer C. When to use which user-experience research methods. Nielsen Norman Group. 2014 Oct 12. https://www.xdstrategy.com/wp-content/uploads/2018/08/When-to-Use-WhichUser-Experience-Research-Methods-2014-10-12-Print.pdf accessed 4 July 2020

8 Gerber E. Tech break up: a research method for understanding people's attachment to their technology. In: Proceedings of the 8th ACM conference on Creativity and cognition 2011 Nov 3 (pp. 137-146).

9 Scherer KR. What are emotions? And how can they be measured?. Social science information. 2005 Dec;44(4):695-729.

10 Rimell V. Ovid's lovers: desire, difference and the poetic imagination. Cambridge University Press; 2006 Jun 15

11 McNaughton N. Discourse (s) of emotion within medical education: the ever-present absence. Medical Education. 2013 Jan;47(1):71-9.

12 Artino Jr AR. When I say... emotion in medical education. Medical Education. 2013 Nov;47(11):1062-3.

13 Jeffrey D. Empathy, sympathy and compassion in healthcare: Is there a problem? Is there a difference? Does it matter? Journal of the Royal Society of Medicine. 2016 Dec;109(12):446-52.

14 Howe A, Smajdor A, Stöckl A. Towards an understanding of resilience and its relevance to medical training. Medical education. 2012 Apr;46(4):349-56.

15 Cruess RL, Cruess SR, Boudreau JD, Snell L, Steinert Y. Reframing medical education to support professional identity formation. Academic Medicine. 2014 Nov 1;89(11):1446-51.

16 Hewson MG, Little ML. Giving feedback in medical education: verification of recommended techniques. Journal of general internal medicine. 1998 Feb;13(2):111-6. 
Page 19 of 19

17 Stone J, Moskowitz GB. Non-conscious bias in medical decision making: what can be done to reduce it? Medical education. 2011 Aug;45(8):768-76.

18 Stolper E, van Bokhoven M, Houben P, Van Royen P, van de Wiel M, van der Weijden T, Dinant GJ. The diagnostic role of gut feelings in general practice A focus group study of the concept and its determinants. BMC Family Practice. 2009 Dec 1;10(1):17.

19 Sandars J. The use of reflection in medical education: AMEE Guide No. 44. Medical teacher. 2009 Jan 1;31(8):685-95.

20 Hodges BD. Sea monsters \& whirlpools: Navigating between examination and reflection in medical education. Medical teacher. 2015 Mar 4;37(3):261-6

21 Lowe G. Health-related effects of creative and expressive writing. Health Education. 2006.

22 Brown M, Dueñas A. A Medical Science Educator's Guide to Selecting a Research Paradigm: Building a Basis for Better Research. Medical Science Educator. 2019:1-9.

23 Rees C, Crampton P, Monrouxe L. Re-visioning academic medicine through a constructionist lens. Acad Med. 2020.

24 Scott S. Negotiating identity: Symbolic interactionist approaches to social identity.: John Wiley \& Sons; 2016.

25 Barton D, Hall N. Letter writing as a social practice. John Benjamins Publishing; 2000 Apr 15.

26 Feilzer Y. Doing mixed methods research pragmatically: Implications for the rediscovery of pragmatism as a research paradigm. Journal of mixed methods research. 2010;4(1):6-16.

27 Stalmeijer R, McNaughton N, Van Mook W. Using focus groups in medical education research: AMEE Guide No. 91. Medical Teacher. 2014;36(11):923-39.

28 Altikriti S. A Pragmatic Analysis of Hyperbole in John Keats ${ }^{e e}$ Love Letters to Fanny Brawn. Journal for the study of English Linguistics. 2016;4(1):126-43.

29 Clarke V, Braun V, Hayfield N. Thematic analysis. Qualitative psychology: A practical guide to research methods. 2015 Jan 1:222-48 
Page 1 of 19

\section{Love and Breakup Letter Methodology: A New Research Technique for Medical Education}

Authors:

William F Laughey*a, Megan EL Brown ${ }^{a}$, Ariel Liut ${ }^{b}$, Angelique N Dueñas ${ }^{a}$ and Gabrielle M Finn $^{\mathrm{a}, \mathrm{c}}$

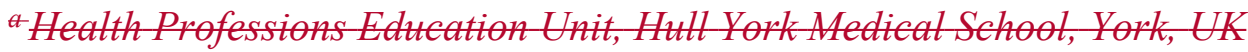

${ }^{b}$ Google Ine, Mountain View, California, USA

¿Division of Medical Education, School of Medical Sciences, Faculty of Biology, Medicine and Health, The University of Manchester, Manchester, UK.

*Corresponding author contact details: William.Laughey@hyms.ac.uk

Health Professions Education Unit, Hull York Medical School, York, YO10 5DD, UK

Biographical notes:

William F Laughey is a General Practitioner and clinical tutor.

Megan EL Brown is a PhD-student in medicaleducation.

Ariel Liu is a Staff User Experience Researcher at Google.

Angelique N Dueñas is a $\mathrm{PhD}$ student in medical education.

Gabrielle M Finn is a professor of medical education and vice-dean for teaching, learning and students. 
Page 2 of 19

(Words 3420362, excluding boxes and tables.)

\section{Introduction}

We have recently utilised Love and Breakup Letter Methodology (LBM) ${ }^{1,2}$ in medical education research ${ }^{3}$, the first time this has been reported in the literature. LBM was developed within the discipline of User Experience (UX) ${ }^{4}$, where it is typically used as a tool to capture what focus group participants like or dislike about technological features or sites. ${ }^{2}$ Research participants are asked to write a love or breakup letter before, or at the beginning of, the focus group. They read their letter aloud to the rest of the participants, and the points expressed within their letters then form the prompts for the focus group discussion that follows. ${ }^{2}$ In this paper, we set out the theoretical considerations for LBM, consider its background in UX, and discuss its practical use in medical education.

\section{$L B M$ in $U X$}

UX first came to prominence in the mid 1990s and since has grown into a buzzword for the Human- Computer Interaction (HCI) among community practitioners and researchers who focus on understanding and improving the human computer interface ${ }^{5}$. As technology advances, UX research has gone beyond typical usability studies or interviews, and now centres on understanding a user's emotional and internal state in relation to "the designed 
Page 3 of 19

system and the context within which the interaction occurs. "' UX research methodology has also been used outside of technology, notably in libraries, where it has been used to influence the design of library space and the services on offer. ${ }^{6}$ Many qualitative UX research methodselogies will be familiar to medical educators, including individual interviews, observational field studies, diary studies, and focus groups. ${ }^{7,8}$

LBM is based on the premise that users form emotional attachments to their devices, apps, and websites - they have feelings for them ${ }^{8}$. These feelings are important as they can change the human decision-making process. For example, feelings can dictate whether a user remains loyal to a brand, or switches to another ${ }^{1}$. Although LBM is concerned with both feelings and emotions, there are differences between the two. Definitions of emotions and feelings are complex and contested, and it is beyond the scope of this paper to consider these in detail. Generally, emotions are viewed as powerful reactions involving syncronised changes to physical and mental functions, linked with neuro endocrine and autonomic changes such as those found in the fight or flight response ${ }^{9}$. Feelings are one component of emotions, and operate at the more conscious and subjective level of the cognitive appraisal of emotional states ${ }^{9}$. Given that LBM requires participants to articulate their thoughts about their attachments to technologies, it may also encourage them towards some subjective, cognitive appraisal of their emotions - in other words, help translate their emotions to feelings.

Love and break up letters are age-old techniques for getting feelings and emotions out in the open. ${ }^{1}$ The literature of love letters dates back to at least the ancient Roman period ${ }^{10}$. LBM is able to exploit this traditional device for the airing of feelings by asking participants to personify the concept under study and make this the object of the letter. As Gerber suggests, 
Page 4 of 19

LBM helps participants express feelings they otherwise might struggle to articulate in more traditional interview-based approaches ${ }^{8}$.

\section{LBM and Medical Education}

LBM should also have utility in medical education, because feelings are central to many of its key concepts ${ }^{11,12}$, including clinical empathy $;{ }^{13}$ resilience; ${ }^{14}$ professional identity formation; ${ }^{15}$ feedback; ${ }^{16}$ and questions of bias ${ }^{17}$. Even in the more deductive areas of medical practice, such as clinical reasoning, feelings have their part to play. ${ }^{18}$ Potentially, then, there is a wide field of educational research to which LBM could reasonably be applied.

As with UX research, we anticipate that love and breakup letters in medical education will be most naturally utilised within the focus group setting. By effectively providing an audience, the public nature of focus groups sharpens anticipation for the creative writing and recital components of LBM. In our experience, this modest sense of theatre raises the energy of the focus group meeting as a whole, elevating enthusiasm for the discussion that ensues.

However, there is no reason to limit the use of LBM exclusively to focus group methodology.

Considered as a more flexible concept, love and break-up letters have relevance for survey design, individual interviews, and programme evaluation.

Love and break up letters could also be considered as a form of standalone reflective writing. While such letters may not form the typical template for medical reflection, they do none-theless capture the author's lived experiences, thoughts, and feelings. As such, they are aligned 
Page 5 of 19

with the aims of reflective writing in medical education ${ }^{19}$ and offer a refreshing alternative to formulaic reflective templates that risk undermining the value of educational portfolios. ${ }^{20}$ Furthermore, expressive writing of this kind has been linked to improvements in mental health and well-being. ${ }^{21}$

\section{LBM and paradigms}

Epistemologically and ontologically, users of LBM make several assumptions. Love and breakup letters are subjective "discursively constructed tales of emotion," which do not allow objective verification of a participant's exact feelings. ${ }^{1}$ As such, their use best aligns with constructivist ways of viewing the world. Constructivism maintains that there is no one objective reality or way of knowing, instead individuals subjectively construct reality and knowledge. ${ }^{22}$

LBM may also fit with constructionist understandings of the world. Constructivism and constructionism are often used interchangeably, but they do differ. ${ }^{23}$ Whilst constructivism focuses on the individual, constructionism is concerned with groups. Maintaining that reality and knowledge exist within social interactions, constructionism posits that these entities are co-constructed in the space between individuals. ${ }^{24}$ Letter writing is a social endeavour, ${ }^{25}$ and the group discussion of love and breakup letters can be used, through a constructionist lens, to explore how individuals co-construct meaning as a collective. 
Page 6 of 19

Finally, LBM also suits use within a pragmatic paradigm, a way of conducting research focusing on problem solving within the 'real world'. ${ }^{26}$ In the post-paradigm war era, researchers in the pragmatic paradigm accept the combination of post-positivist and constructivist approaches within the same research study, usually in the form of mixedmethods design incorporating both quantitative and qualitative elements ${ }^{26} . \underline{\text { A survey-based }}$ $\underline{\text { study collecting both quantitative and qualitative data could include an invitation to write a }}$ love or break up letter as part of the qualitative data-gathering. Within UX, LBM is often combined with methods that adopt quantitative approaches, such as card-sorting ${ }^{2}$, typifying a pragmatic approach. For example, when researching an app, LBM is employed to understand how users relate to the product, while card sorting - a method in which participants group information written on cards in ways that make sense to them ${ }^{2}$ - is employed to explore how users prefer content to be displayed. For example, LBM focus groups could be combined with a questionnaire survey within a pragmatic, mixed-methods study. Indeed, within UX, LBM is often combined with methods that adopt quantitative techniques, such as card-sorting ${ }^{2}$, typifying a pragmatic approach.

\section{LBM in practice}

LBM is inherently flexible, so researchers in medical education have options as to how they wish to adapt the approach to their particular area of study. To guide the reader further, we will first consider the archetypal approach to running an LBM focus group in UX, then we will describe how we have adapted this for research in medical education. 
Page 7 of 19

Practice points from a UX researcher

As industry UX researchers collect data that is commercially sensitive, few studies concerning such data have been published in peer-reviewed journals. The literature, therefore, provides only superficial details of how the LBM methodology is employed in UX. Thus, as an illustrative aid, we have included these practical considerations from a staff UX researcher at a technology company (one of the authors, AL, from this paper).

One important fact to note is that in the technology sector, LBM is often used in conjunction with other activities, such as interviews or Card Sorting ${ }^{2}$, as part of a co-creation workshop with participants. These combinations are motivated either by a concern for participant fatigue caused by an activity that extends for a longer duration, or by the desire to keep them engaged with the topic areas. Typically, researchers follow these steps:

1. To examine participants' emotions about an aspect of technology, participants are often asked to interact with the platform or feature from their mobile devices for the first five minutes of the session. Each participant is then asked to spend no more than fifteen minutes writing a short love or breakup letter about this experience. The goal is to capture participants' immediate thoughts and emotions when engaging with the platform or feature. To avoid confusion or embarrassment, a simple example letter is exhibited in front of them to boost participant confidence.

2. When the letters are completed, the facilitator records each participant reading aloud their letters to their phones as if they were sending video messages. This approach 
Page 8 of 19

heightens participants' emotions, and sometimes, it brings out the humorous aspects of the experience.

3. Each time a participant finishes reading a letter, the facilitator asks other participants to raise their hands if they feel the same way and then asks the author follow-up questions. This review process not only helps the participants get to know each other, but it also makes the discussion environment more relaxed, conversational, and relatable. The facilitator, who is often the researcher, has a critical role in this activity. When the participants are not as vocal, the researcher must come up with prompts to promote deeper dialogue and eption-sharing.

4. In the workshop, there is often another researcher who acts as the note-taker, capturing the key topics discussed in addition to the letters.

5. Occasionally, after the LBM activity, participants are asked to participate in an ideation phase and redesign their ideal relationships to amend or improve their relationships with the platform or feature at issue. This helps the researcher identify the trade-offs and challenges from the users' perspectives as well as the potential solutions, or at least gain a deeper understanding of the problems.

\section{Practice points in medical education}

In studying clinical empathy ${ }^{3}$, we adopted the following three-step approach to LBM in medical education: 
Page 9 of 19

1. Participants wrote their love and break up letters to the concept under study (e.g., 'empathy for patients,' which was our concept being researched) at the beginning of the meeting. We asked for both a love letter and a breakup letter from each participant. Letters were hand-written, though the option of writing electronically saves transcribing. We allowed 20-30 minutes for writing.

2. Letters were read aloud, in turn, by their authors. Participants read their love letter first, and when all love letters had been read, they moved onto the breakup letters. The research team noted key messages and other relevant field observations but held off from instigating any discussions until all letters had been read.

3. The facilitator used the letters and their messages as the triggers for the focus group discussion. A typical discussion time was 50 minutes.

The task of letter writing usually takes place at the beginning of the session with the researchers in the room. This allows for the opportunity of explaining the letter-writing task, answering any questions, and generally making sure that participants are comfortable with what is required. Session time could be saved by asking participants to bring pre-written compositions, but this option would not provide the same in-person clarification about the letter-writing process.

Researchers have a choice as to whether to ask participants to write either a love letter or a breakup letter, to compose a single letter that starts with love and moves to break up or to write both a love letter followed by a breakup letter. We chose the latter method, reasoning it would help participants consider both sides of the argument and perhaps encourage a more 
Page 10 of 19

balanced discussion. In UX, it is common to give participants the choice of either love or break up, partly in the interests of time, partly because it may be more acceptable to participants, and also because it is interesting to know from the beginning which way participants are leaning.

In our study, we elected for all letters to be recited before commencing the discussion. We reasoned this would prioritise the collective discussion element over the individual letters, following a more traditional focus group approach in medical education. This approach may also work better for groups in which power or hierarchy merit consideration, such as focus groups with interprofessional learners. If taking the alternative approach of inviting discussion after each letter, a participant who feels lower in the hierarchy may be reluctant to read a letter that contains ideas that have already been adversely received by those at the top of the hierarchy. However, there may be instances where researchers feel that the individual contributions in the letters should be prioritised over the fluidity of a continuous group discussion, in which case inviting discussion after each letter would make more sense.

In UX, letter reading is often video recorded ${ }^{2}$. Though in our use in medical education, we elected to use audio recording for the letter readings and focus group discussion. We reasoned that video recording would add an extra layer of embarrassment to an activity that might already feel daunting for shy participants. However, by providing the opportunity to consider body language, video recording may allow researchers to better understand any unspoken messages, "to read between the lines" of the letters.

In UX, participants recite their letters to their smart phones. The phone here works largely as a prop, helping with the aspect of performance. Phones can also capture video recordings, 
Page 11 of 19

which UX researchers use to enhance the presentation of their findings within their company meetings. Anticipating our output would be a written paper, we elected not to capture any video and did not ask participants to recite to their phones. In retrospect, we may have missed an opportunity to enhance the presentation of findings at an academic conference.

As with any other type of focus group, the role of the facilitator merits consideration. The facilitator has all the usual responsibilities common to focus groups, such as encouraging contributions from all participants, ${ }^{27}$ but in addition, they also need to be alert to the potential for embarrassment associated with letter reading. In our limited experience in medical education, embarrassment is often less of a problem than might be anticipated. However, this comes with the caveat that we recruited groups of students who often knew each other, having studied together for several years. In addition, one researcher (WFL) was known to several participating students as a phase one tutor, which may also have helped participants accept the methodology.

The facilitator, aided by the research team, also needs to be alert to the key messages apparent in the letters, as these will form the triggers for the discussion to follow. The wider research team should make field notes during the discussion, supporting the facilitator in identifying key messages and noting non-verbal communications that are lost with audiorecording.

Finally, recognising that LBM is more likely to be used for emotive areas of study, the facilitator and the research team as a whole need to be alert to the possibility of participants becoming uncomfortable or feeling distressed at any point in the research meeting. The 
Page 12 of 19

consent process should accommodate this potential concern and detail procedures for debriefing afterwards should this be needed.

\section{LBM Merits and Limitations}

We believe that LBM has a number of merits. Used in conjunction with focus groups, LBM ensures that all members of the group contribute their initial thoughts. These thoughts have not yet been subject to group influence, so they represent valuable, individual contributions. In this way, LBM mitigates a general limitation of focus groups, that quieter participants might be overshadowed by more vociferous members of the group. ${ }^{27}$

Letter writing requires the use of heightened language, including literary devices, such as personification, hyperbole, metaphor, and rhyme. ${ }^{28}$ This figurative language captures richer messages, which themselves translate to richer data for analysis. Medical education, like UX research, deals with abstract constructs. Personifying the abstract - for example, "empathy for patients" - and inviting creative writing centred on feelings and emotions is certainly an interesting and engaging way of inviting discussion. In our experience, the letters are often both captivating and humorous. They act both to raise interest in the topic and serve as "ice breakers" for the discussion to follow. In our medical education research, students generally took to the task of letter writing with enthusiasm and no small amount of artistic flair. ${ }^{3}$ We have included examples of two letters by way of illustration. (Box 1).

Conversely, it is also important to consider the limitations of LBM. By their nature, love and breakup letters are dichotomous, risking a focus on opposing ends of the spectrum and missing the shades of grey in between. As already discussed, some participants are less 
Page 13 of 19

comfortable with creative writing and potentially may be embarrassed to read their letters. This warrants consideration during the process of consent. In terms of practicalities, letter writing increases the duration of the focus group, adding 20-30 minutes in the empathy study (though generally a little less time, around 10-15 minutes, is used in UX research).

Case studies in Medical Education

1 Focus Group

Within medical education, we used LBM in a focus group setting to research medical students' thoughts and feelings on the practice and teaching of clinical empathy. ${ }^{3}$ We asked for love and breakup letters regarding the concept of empathy for patients. We ran three focus groups and analysed the written letters and the discussion transcripts together, using Thematic Analysis. ${ }^{29}$ Almost all of the student participants warmed to the task of letter writing, producing remarkable compositions (Box 1). The letters, and the discussions they prompted, provided rich data for analysis. The method worked well for getting to the root cause of the matter. For example, we quickly uncovered the problem of making fake empathic statements ${ }^{3}$.

We also had the opportunity to conduct LBM online. The third focus group was conducted using video-conferencing software, due to the social distancing restrictions mandated in the wake of COVID-19. Online focus groups are by no means a new concept ${ }^{27}$, and they will be more necessary through the duration of the pandemic and may remain more popular after it. Perhaps the most noticeable difference came during the process of letter reading. Extraneous 
Page 14 of 19

noises and feedback interrupted one reading, so as a group we switched to mute to hear the letters without background interruptions. However, this also reduced the sense of support, as well as the warmth and laughter that typically accompanies an in-person reading. None-theless, letters and discussion yielded data just as rich as those from the first two focus groups, and the recording feature built into the video-conferencing software meant we could capture both audio and video with ease.

\section{In Programme-Level Research}

LBM can also be modified for use alongside other qualitative methods, outside of focus groups. We have also used LBM as open-ended response questions in a qualitative survey researching the impacts of a large-scale widening access programme intended to give participants from relatively under-privileged backgrounds access to medical school. Participants were asked to write love and break-up letters to their programme, in lieu of more traditional 'positive' and 'negative' experience questions. While simple, this use of LBM highlighted the power of personification. Responses were emotive, with participants having to personify their participation in the programme. As part of this research study, semistructured interviews were then conducted to follow-up with some participants. Similar to their use in focus groups, the letters also provided an excellent stimulus for discussion, to help guide participant reflection about their lived experiences.

\section{LBM in Teaching Evaluations}


Page 15 of 19

Following the success and insight from using LBM in programme-level research, we also employed LBM in more small-scale, routinely collected programme evaluation. A novel professionalism and ethics ten-week workshop series was created. To assess the innovation, each week, students were informally asked to write a love and break-up letter to the content and activities covered in that session. However, this means of using LBM highlighted some limitations. With limited time, and when prompted to reflect on specific content, this methodology did not produce responses beyond what may have also been elucidated via more simple evaluation. Additionally, as students repeated feedback weekly, detail in response waned. This warrants consideration of the possible longitudinal value of LBM for other topics or types of research; LBM might best be utilised in singular, cross-sectional research.

In summary, our experience highlights the power of LBM, particularly when used in multimethods approach to research or evaluation. While letters can be powerful alone, insights are even greater when investigators have the opportunity to use letters as a springboard for discussion. Applied judiciously, with due consideration for merits and limitations ( $\underline{\text { Box }}$ 1Table 1), LBM has clear potential for use in research and evaluation within medical education.

\section{BoxTable 1: Merits \& Limitations of LBM}

Merits

- Ensures individual contributions from all participants

- Acts as an icebreaker since the letter reading encourages smiles and laugher 
Page 16 of 19

- Creative writing \& recitals elevate interest and engagement, fuelling focus group discussion

- Aligns with the practice of reflective writing, an already well-established tool in medical education

- Provides additional rich data from the letters for analysis

\section{Limitations}

- Risk of dichotomous data and neglected shades of grey

- Socially uncomfortable for some participants

- Extends duration of focus group session

- Less well suited to repetitive use in longitudinal approaches

\section{Box 2: Sample Letters}

\section{Love}

Empathy, I love you, you're the most real and important factor in a consultation. You're strong and powerful and your presence can make everything more interesting. Although you are often absent, I know our time together is invaluable. When you're around, I listen more, care more, and learn more. The more I have got to know the real you, the more in love I am. I still remember the first time we met, it was on the gastro ward, the sun was streaming in 
Page 17 of 19

through the window and I felt you, it was real love. I still remember that consultation and I hope we have the rest of our lives together.

Lots of love, $x x x$

\section{Breakup}

Dear Empathy...

You will always hold a place in my heart,

But it breaks me to say, I'm afraid we must part.

You've always been there, always something to say,

But for me, I'm afraid, that is just not $O K$.

Silence speaks volumes, it allows time to think,

Not just empty fillers, like a carbonated drink.

You have so much potential to really have meaning,

But forced words is the way you are leaning.

I know there's someone out there for you,

You need to be yourself, don't change, stay true.

You have so many wonderful qualities to see,

But I am sorry, Empathy, you are just not for me.

References 
Page 18 of 19

1 Koskinen K, Ruokonen M. Love letters or hate mail? Translators' technology acceptance in the light of their emotional narratives. In: Human issues in translation technology 2017 Jan 12 (pp. 26-42). Routledge.

2 Hanington B, Martin B. Universal methods of design: 100 ways to research complex problems, develop innovative ideas, and design effective solutions. Rockport Publishers. 2012.

3 Laughey WF, Brown ME, Dueñas AN, Archer R, Whitwell MR, Liu A, Finn GM. How medical school alters empathy: Student love and break up letters to empathy for patients. Medical Education. 2020 Oct 30.

4 Hassenzahl M, Tractinsky N. User experience-a research agenda. Behaviour \& information technology. 2006 Mar 1;25(2):91-7.

5 Lallemand C, Gronier G, Koenig V. User experience: A concept without consensus? Exploring practitioners' perspectives through an international survey. Computers in Human Behavior. 2015 Feb 1; 43:35-48.

6 Schmidt A, Etches A. User experience (UX) design for libraries:(THE TECH SET®\# 18). American Library Association; 2012.)

7 Rohrer C. When to use which user-experience research methods. Nielsen Norman Group. 2014 Oct 12. https://www.xdstrategy.com/wp-content/uploads/2018/08/When-to-Use-WhichUser-Experience-Research-Methods-2014-10-12-Print.pdf accessed 4 July 2020

8 Gerber E. Tech break up: a research method for understanding people's attachment to their technology. In: Proceedings of the 8th ACM conference on Creativity and cognition 2011 Nov 3 (pp. 137-146).

9 Scherer KR. What are emotions? And how can they be measured?. Social science information. 2005 Dec;44(4):695-729.

10 Rimell V. Ovid's lovers: desire, difference and the poetic imagination. Cambridge University Press; 2006 Jun 15

11 McNaughton N. Discourse (s) of emotion within medical education: the ever-present absence. Medical Education. 2013 Jan;47(1):71-9.

12 Artino Jr AR. When I say... emotion in medical education. Medical Education. 2013 Nov;47(11):1062-3.

13 Jeffrey D. Empathy, sympathy and compassion in healthcare: Is there a problem? Is there a difference? Does it matter? Journal of the Royal Society of Medicine. 2016 Dec;109(12):446-52.

14 Howe A, Smajdor A, Stöckl A. Towards an understanding of resilience and its relevance to medical training. Medical education. 2012 Apr;46(4):349-56. 
Page 19 of 19

15 Cruess RL, Cruess SR, Boudreau JD, Snell L, Steinert Y. Reframing medical education to support professional identity formation. Academic Medicine. 2014 Nov 1;89(11):1446-51.

16 Hewson MG, Little ML. Giving feedback in medical education: verification of recommended techniques. Journal of general internal medicine. 1998 Feb;13(2):111-6.

17 Stone J, Moskowitz GB. Non-conscious bias in medical decision making: what can be done to reduce it? Medical education. 2011 Aug;45(8):768-76.

18 Stolper E, van Bokhoven M, Houben P, Van Royen P, van de Wiel M, van der Weijden T, Dinant GJ. The diagnostic role of gut feelings in general practice A focus group study of the concept and its determinants. BMC Family Practice. 2009 Dec 1;10(1):17.

19 Sandars J. The use of reflection in medical education: AMEE Guide No. 44. Medical teacher. 2009 Jan 1;31(8):685-95.

20 Hodges BD. Sea monsters \& whirlpools: Navigating between examination and reflection in medical education. Medical teacher. 2015 Mar 4;37(3):261-6

21 Lowe G. Health-related effects of creative and expressive writing. Health Education. 2006.

22 Brown M, Dueñas A. A Medical Science Educator's Guide to Selecting a Research Paradigm: Building a Basis for Better Research. Medical Science Educator. 2019:1-9.

23 Rees C, Crampton P, Monrouxe L. Re-visioning academic medicine through a constructionist lens. Acad Med. 2020.

24 Scott S. Negotiating identity: Symbolic interactionist approaches to social identity.: John Wiley \& Sons; 2016.

25 Barton D, Hall N. Letter writing as a social practice. John Benjamins Publishing; 2000 Apr 15.

26 Feilzer Y. Doing mixed methods research pragmatically: Implications for the rediscovery of pragmatism as a research paradigm. Journal of mixed methods research. 2010;4(1):6-16.

27 Stalmeijer R, McNaughton N, Van Mook W. Using focus groups in medical education research: AMEE Guide No. 91. Medical Teacher. 2014;36(11):923-39.

28 Altikriti S. A Pragmatic Analysis of Hyperbole in John Keats ${ }^{e e}$ Love Letters to Fanny Brawn. Journal for the study of English Linguistics. 2016;4(1):126-43.

29 Clarke V, Braun V, Hayfield N. Thematic analysis. Qualitative psychology: A practical guide to research methods. 2015 Jan 1:222-48 


\section{Supplementary material}

\section{Further examples of love and break up letters to 'empathy for patients'}

\section{Love letter:}

Dear empathy,

You are one of the reasons I applied for medical school. I liked the idea of understanding people; knowing what makes people tick and how the state of a person's mind changes with illness. This interest in empathy, an appreciation for its value and its clinical validity has greatly changed during the course at HYMS. Now, finally in my final year, I feel I have come full circle with you. This is thanks to my GP placement at Grimsby. I did not pick up very visible cues of how stressed a patient was, something the GP immediately picked up on when he asked how everything was going. She immediately started crying and broke down. I started doing the same, it was amazing the wealth of information a few questions could bring. Patients in places like Grimsby have problems that I cannot relate to or understand, have stressors and chaotic lives that I have not appreciated. This reminded me of why I wanted to do medicine in the first place. It made me feel like I was doing better for my patients and made me feel more satisfied.

\section{Love letter:}

My love, my light, the force that grounds me. You encourage me to dig to the deepest, darkest, murkiest depths of my cynical soul. So thank you. When I feel as though 4 years of relentless, harrowing patient encounters has left me with nothing more to give, you push my jaded being into healing and kindness, so thank you. On the days where emotions are too much and I succumb to the warm allure of numbness, empathy, it is you that lights the path to feeling again. Thank you.

Empathy, it is because of you that when I run out of things to say, I can carry on for the sake of others. Ideas, concerns, and expectations of others is the centre of your being, and it is that selflessness that has drawn my selfish soul to you.

You truly are the ying to my yang. How the days without you lack purpose and reflection! The world revolving around me like the Earth revolves around the sun is only so exciting for so long; looking into the deep well of others' feelings provides emotional fuel like no other.

I love you more than garlic and herb dip,

X (Lipstick kiss on paper) 


\section{Break-up letter:}

I am so done, so done. I just don't care anymore. You are draining, you take all my energy and require so much from me. I can't continue this way. I've been faking it.... for so long. I know I promised I wasn't, but I can't hide it anymore. Day after day, patient after patient, tears after tears. I can't do it all the time. Then there's the guilt, when I should have invited you but I couldn't be bothered. That's most of the time now, I can't be bothered because I can't stand you. Alas, I know I have myself to blame as well, I don't pay enough attention, I don't believe people as easily, tears mean less to me. It's also the outside pressure, the judging looks from consultants and GPs when we're together and we're taking too long. You can tell the further along we get in this degree, the less people care about you. I know how wrong that is, and I shouldn't care what people think- but I do. Ultimately it has to end, before we get too hurt. 